\title{
Finding stable support for computing in psychology: Lessons from innovation diffusion in organizations
}

\author{
CHARLES W. HUFF and JAMES F. DICKSON, JR. \\ St. Olaf College, Northfield, Minnesota
}

\begin{abstract}
We present the steps that the Psychology Department, the Academic Computing Center.(ACC), and the central administration at St. Olaf College have taken to integrate computing support into the operating budget of the college. In hindsight, we also propose a model of the diffusion of innovations into an organization as a theoretical guide to stabilizing support for computing in academic departments. The theoretical framework highlights the commonality between our particular adaptations and those that would most help at other institutions.
\end{abstract}

Fifteen years ago, I proposed a laboratory of minicomputers that would be networked to a master so that students could work on their machines while I sat back, watched, and interacted with them. Fortunately we did not get the grant.

$$
\text { -M. D. Glick }
$$

Professor Glick's (1990) admission of relief at not getting his computing grant shows unusual candor and wisdom. Researchers in educational computing have documented the frustrations associated with unsupported new equipment (Rogers, McManus, Peters, \& Kim, 1985; Schofield \& Verban, 1988; Watkins \& Brim, 1985). Rogers (1986), for instance, reports the following comment by a disgruntled administrator whose high school had just received a minicomputer requiring $\$ 300$ a month preventive maintenance: "One more gift like that and we'll go under." Those of us who administer and use computing laboratories in colleges can feel some of the resonance of this complaint. As Hammond and Trapp (1991) have observed, there is only a little integration of computing in teaching, and even less integration in terms of internal organizational support for computing in psychology departments.

In this paper, we present the steps that the Psychology Department, the Academic Computing Center (ACC), and the central administration at St. Olaf College have taken to try to integrate computing support into the ongoing operating budget of the college. In hindsight, we also propose a model of the diffusion of innovations into an organization as a theoretical guide to stabilizing support for computing in academic departments.

Work on this paper was partially supported by NSF ILI Grant 88 51795 to James Dickson. Thanks to the Academic Computing Center at St. Olaf for support in computing resources, time, and advice. Blake Sobiloff read and commented on earlier versions of this paper. Requests for reprints should be sent to Chuck Huff, Department of Psychology, St. Olaf College, Northfield, MN 55057.

\section{The Current Psychology Laboratory}

An NSF Instrumentation and Laboratory Improvement award provided funds to establish the first laboratoryclassroom computer network at St. Olaf College. This award came at a time when the college administration was placing increased emphasis on computing facilities (e.g., they had just appointed the first full-time ACC director). During the summer of 1988 , the college remodeled a large room in the psychology building and furnished it with laboratory furniture and cabinets. Most of the hardware and software purchases were also made during the summer of 1988-mostly with NSF funds, but funds for software, cabling, and some hardware came from the ACC. Thus the psychology computing lab was a collaborative effort from its inception.

Facilities. Shortly after the beginning of the 1988-1989 academic year, the laboratory was available for student and faculty use. The Academic Computer Center realized that having computers available to students but not available to faculty would hamper any faculty participation in the lab. The Center made it a goal over a 2-year period to provide every faculty member with a computer linked to a local network and to the laboratory-classroom machines, a fileserver, and a laser printer.

Use of the lab. During the past 2 years, several classes have made extensive use of the facilities. Laboratory courses in experimental psychology (e.g., sensation and perception, behavior principles, cognition, learning, and memory), biopsychology (i.e., physiological psychology, and comparative psychology), and research methods have used the facility for tasks ranging from stimulus presentation and contingency programming to data analysis, graphical presentation, and report writing. Students doing research in their senior year have used the lab facilities to collect and analyze data and to prepare presentations for conferences. Because of the joint funding, the lab is also open at least $12 \mathrm{~h}$ a week, in the evenings, to the campus community. 
Budgeting for support. Software for the lab is funded jointly by the NSF funds and a yearly software budget provided by the ACC. When the NSF funds expire, the ACC will take over all funding of software. The small yearly software budget does not allow major purchases, but it does allow us to acquire software for rigorous "test runs." When we find software adequate for our needs, the ACC assists in buying it in quantity. For instance, our review of a statistics package led to its adoption by the Departments of Psychology, Biology, and Mathematicsenough users to make a site license affordable.

With the ACC funds, we have begun yearly upgrades of $20 \%$ of our hardware to current machines. Suitable software and hardware upgrades for a $\$ 3,000$ machine can likely extend the useful life of that machine to about 5 years (Weissman, 1989). These upgrades, plus maintenance, should cost another $\$ 3,000$-making the total 5year cost for the machine $\$ 6,000$. Thus, by upgrading $20 \%$ of the hardware every year, we ensure that no machine is older than its useful life.

Paper, ribbons, toner cartridges, and other supplies come from the Psychology Department's budget, whereas minor and major repairs come from the ACC budget. The ACC is better able to assume the cost of, say, a hard disk crash, by distributing it over the entire college budget. This creates a sort of insurance pool in case of major repair expenses.

The Psychology Department and the ACC jointly fund the salary of a 15-h per week student lab assistant. This assistant keeps inventory, upgrades software, provides heip with software and hardware for faculty and staff, and supervises the opening and closing of the lab. The lab assistant reports to both a psychology faculty supervisor and an ACC supervisor. Thus, in personnel as in most other areas, the computing lab facilities are a joint venture of the Psychology Department and the ACC.

\section{Diffusion in Organizations}

Looking back on the way in which our computing lab became an integral part of both the ACC and the Psychology Department's budgets, we think that this process fits a model of organizational innovation proposed by Rogers (1983). The process by which an innovation is identified, adopted, modified to fit, and then integrated in an organization has been presented in a schematic model by Rogers (1983). Figure 1 is an explanatory representation of this process. Two larger stages, initiation and implementation, are conceptually separated by the actual decision to adopt the innovation (in this case, computers).

The initiation stage is essentially an information-seeking and decision-making process. Rogers's (1983) presentation of initiation seems overly rational (identify a problem, search for an innovation, match properties of the problem and the innovation)-particularly for the adoption of computers.

The implementation stage involves modifying both the innovation (e.g., writing or modifying software) and the organization (e.g., making new staff positions in computing) in order to integrate or "routinize" the use of the innovation in the organization. Those of us who now have computing labs are clearly in the implementation stage and are working on making our organizations and our computers fit each other. The important thing about the implementation stage is that it is really a process of making the innovation no longer "innovative." It is making the new into the routine: an expected part of the organizations's work-and budget.

There are three steps in the latter part of the model, but again, it is an idealization of the actual process and can only roughly correspond to the actual complexity of any particular innovation (Kraut, Dumais, \& Koch, 1989).

Redefining/restructuring. Rarely do those who use a technology view it in the same light as those who have designed it. A technology is almost always redefined by its users or adopters. For instance, we had originally viewed the computers that we bought as means of teaching students course content. In practice, we found that the machines were used to the greatest extent as tools for collecting data and analyzing and presenting data to others. This use of computing has helped to spur a large increase in the amount of empirical research done by students in our department. Redefining the computers as research tools allows us to view this as a success of the technology, not as a failure of the original intent of content delivery.

Even as users use the technology to fit their needs, the technology initiates organizational changes. These changes can put stress on organizations that do not anticipate them. For instance, though the National Science Foundation was generous in providing hardware, they provided no money for personnel or other support which a functioning computing lab needs. We found ourselves compelled to cooperate with the Academic Computing Center to provide that support. This cooperation led to a jointly administered computing lab-a significant and unforeseen structural change.

Clarifying. Once a technology has established itself in an organization, its position in the organization must be clarified. We are still clarifying the division of responsibilities in our joint Psychology/ACC lab. Though we have routinized the budgeting of salary for our lab assistants (half from the department and half from the ACC), we are still unclear about the lines of command for those lab assistants. Do they report to Psychology, to the ACC, or to both?

Routinization. At this point, the technology is no longer seen as new; it "disappears" into the everyday routine of the organization. The photocopying machine offers a reasonable example of this sort of a routinized technology (Suchman, 1987). In most postsecondary schools, "computerized" data analysis has become so routinized that adding the quoted word seems redundant and awkward. Widespread access to computing for undergraduates is clearly not yet at the same stage (FIPSE Technol- 
The St. Olaf Psychology Lab a. The Innovation Process

Initiation
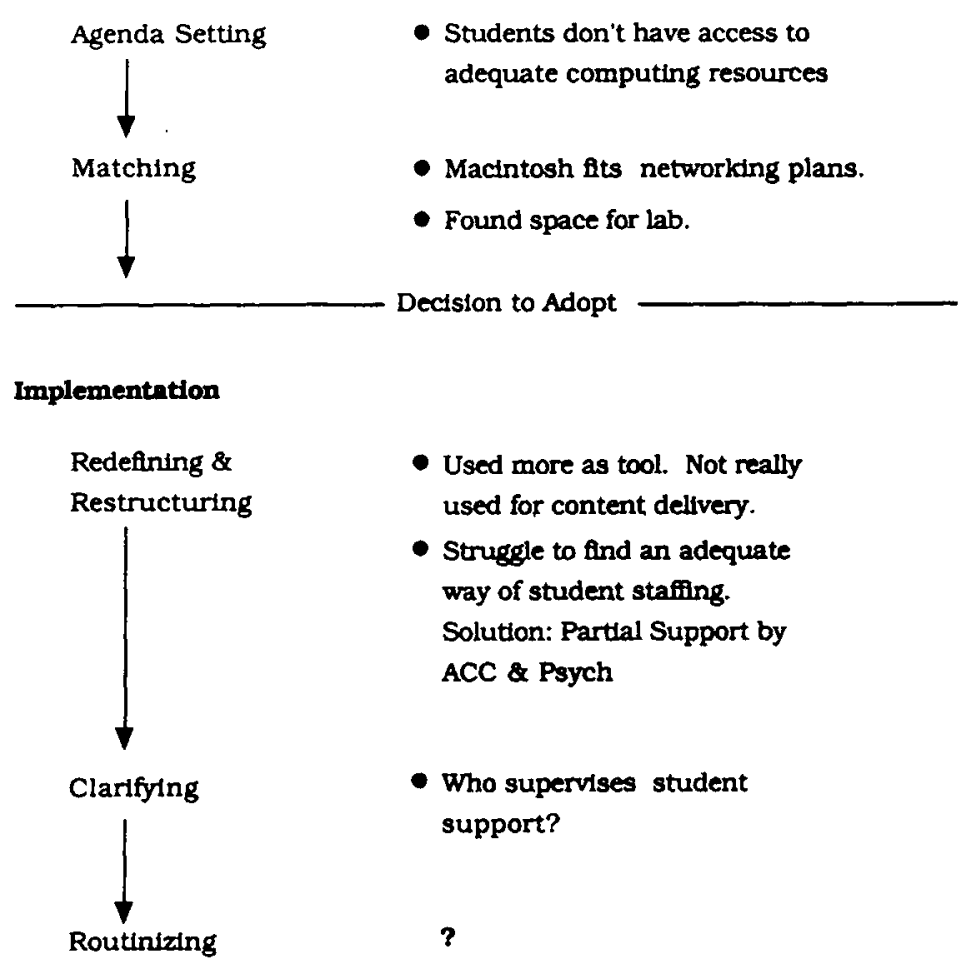

Figure 1. The innovation model applied to psychology computing at St. Olaf.

ogy Study Group, 1988). Institutional support for startup costs and for day-to-day operation of undergraduate computing facilities is often lacking. Only when computing becomes a routine and expected part of undergraduate work will we be likely to find undergraduate microcomputing routinized.

\section{Suggestions from the Model}

Our experience in finding continuing support for a microcomputer lab seems to fit reasonably with Rogers' (1983) framework. The theoretical framework is helpful because it highlights the commonality between our particular adaptations and those that would help most at other institutions. Our particular choices (say, joint administration with the ACC) may not be appropriate for all institutions. But the move toward routinization-whatever the specific form it takes-is essential in ensuring the success of computing in our schools.

The framework encourages us to look beyond the trenches of everyday problem-solving and to consider the longer life of the innovations we introduce. The goal, after all, is not merely to get the latest hardware and software, but to make that technology useful to our students.
In this larger goal, support often plays a more important role than does having the newest hardware (FIPSE Technology Study Group, 1988). The NSF recognizes this in its "Instrumentation and Laboratory Improvement" program-proposals that include realistic plans for continued support are more likely to be funded.

Finally, successful routinization of computing means that we will need to rely less on individual "early adopters" to maintain an innovation. They will need to worry less about logistics and training of faculty and will be able to concentrate on the creative use of the technology.

\section{REFERENCES}

FIPSE TEChNology STUdy Group (1988). Ivory towers, silicon basements: Learner-centered compusing in postsecondary education. Ann Arbor, MI: EDUCOM

Guck, M. D. (1990, summer). Integrating computing into higher education. EDUCOM Review, pp. 35-38.

Hammond, N., TrapP, A. (1991). Computers in psychology teaching in the U.K. Behavior Research Methods, Instruments, \& Computers, 23, 118-120.

Kraut, R., DumaIs, S., \& Koch, S. (1989). Computerization, productivity, and quality of work life. Communications of the $A C M, 32$, 221-238. 
Rogers, E. M. (1983). Diffusion of innovations. New York: Free Press. ROGERs, E. M. (1986). Communication technology: The new media in society. New York: Free Press.

Rogers, E. M., McManus, J. H., Peters, J. D., Kim, J. (1985). The diffusion of microcomputers in California high schools. In $M$. Chen \& W. Paisley (Eds.), Children and microcomputers (pp. 151169). Beverly Hills, CA: Sage.

SChOFIELD, J. W., VERBAN, D. (1988). Barriers and incentives to computer usage in teaching (Tech. Rep. No. 1). Pittsburgh, PA: University of Pittsburgh, Leaming Research and Development Center.
Suchman, L. A. (1987). Plans and situated actions: The problem of human machine communication. New York: Cambridge University Press.

WATKINS, B., \& Brim, D. (1985). The adoption and use of microcomputers in homes and elementary schools. In M. Chen \& W. Paisley (Eds.), Children and microcomputers (pp. 129-150). Beverly Hills, CA: Sage.

Weissman, R. (1989). Capital budgeting and lifecycle planning for desktop technology. In B. L. Hawkins (Ed.), Organizing and managing information resources on campus (pp. 339-366). Ann Arbor, MI: EDUCOM. 